\title{
Hysteresis Control for Shunt Active Power Filter under Unbalanced Three-Phase Load Conditions
}

\author{
Z. Chelli, ${ }^{1,2}$ R. Toufouti, ${ }^{1}$ A. Omeiri, ${ }^{2}$ and S. Saad ${ }^{3}$ \\ ${ }^{1}$ Department of Electrical Engineering, University of Mohamed-Cherif Messaadia of Souk Ahras, P.O. Box 1553, \\ 41000 Souk Ahras, Algeria \\ ${ }^{2}$ Department of Electrical Engineering, University of Badji Mokhtar of Annaba, P.O. Box 12, 23000 Annaba, Algeria \\ ${ }^{3}$ Department of Electromechanical Engineering, University of Badji Mokhtar of Annaba, P.O. Box 12, 23000 Annaba, Algeria
}

Correspondence should be addressed to Z. Chelli; chellizoubir@outlook.fr

Received 8 November 2014; Accepted 10 March 2015

Academic Editor: Muhammad Taher Abuelma’atti

Copyright (c) 2015 Z. Chelli et al. This is an open access article distributed under the Creative Commons Attribution License, which permits unrestricted use, distribution, and reproduction in any medium, provided the original work is properly cited.

\begin{abstract}
This paper focuses on a four-wire shunt active power filter (APF) control scheme proposed to improve the performance of the APF. This filter is used to compensate harmonic distortion in three-phase four-wire systems. Several harmonic suppression techniques have been widely proposed and applied to minimize harmonic effects. The proposed control scheme can compensate harmonics and reactive power of the nonlinear loads simultaneously. This approach is compared to the conventional shunt APF reference compensation strategy. The developed algorithm is validated by simulation tests using MATLAB Simulink. The obtained results have demonstrated the effectiveness of the proposed scheme and confirmed the theoretical developments for balanced and unbalanced nonlinear loads.
\end{abstract}

\section{Introduction}

Power electronic equipments are largely used in modern electrical systems leading to an increase of the harmonics pollution in the AC main supplies. Thus, harmonic currents generated by static converter mainly rectifiers have become a great issue in the field of electrical engineering due to the adverse effects on all electrical equipments [1]. The intensive use of nonlinear equipments has increased the demand for harmonics suppression and reactive power compensation. It has been proved by many reported work that these nonlinear loads are the main cause of poor power factor and high harmonic distortion [2].

The presence of harmonics in the power system results in numerous drawbacks such as high power loss in distribution network, electromagnetic interference in communication systems, and failures of power protection devices and electrical and electronic equipments. These drawbacks can greatly affect the industrial process and commercial activities because they can lead to a decrease in the productivity and can also affect the quality of the products [3]. The harmonics generated by these nonlinear load cause voltage distortion affecting other loads connected at the same point of common coupling.

The APF was deeply studied and applied as an efficient solution to the problem of harmonics pollution and their effects [4]. This type of filters is proved as an appropriate technique to suppress harmonic voltage and current disturbances $[5,6]$.

The APF injects harmonic current (for shunt active filter) or voltage (for serie active filter) into the power source but in opposite direction. Different harmonic current identification and extraction techniques were studied and used [7-10] such as synchronous reference (d-q-0) theory, instantaneous real-reactive power ( $\mathrm{p}-\mathrm{q}$ ) theory, modified instantaneous $\mathrm{p}-\mathrm{q}$ theory, flux-based controller, notch filter, and neural network techniques [10]. Though $\mathrm{p}$-q theory has good transient response time and steady-state accuracy [6], it is found to be not suitable for estimating reference current under nonideal source voltage conditions $[6,11]$. This paper presents an analysis and simulation of shunt active filter under unbalanced nonlinear load. In order to identify shunt APF reference current a novel $\mathrm{p}-\mathrm{q}$ theory is used based on PLL for unbalanced main voltages to control shunt APF. 


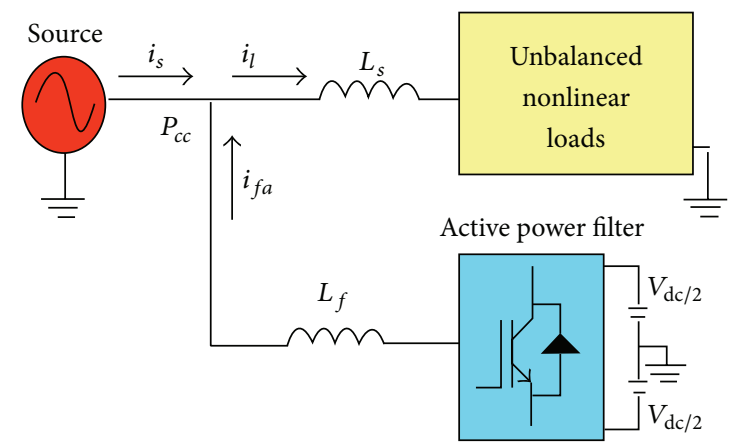

FIGURE 1: Shunt active filter under unbalanced nonlinear load.

Hysteresis controllers are employed to generate switching signals of the voltage source inverter. The proposed active filter can compensate both harmonic currents and reactive power (correcting power factor to the unity) simultaneously. To validate and confirm the developed algorithms for the proposed scheme, simulation tests are conducted to show the effectiveness of this approach.

\section{Shunt Active Filter Basic Principle}

The shunt active power filter operating principle is to inject into the power supply network the same harmonics current as that generated by the nonlinear load but in the opposite direction. Figure 1 illustrates a typical structure of the shunt APF connected to a main source [12].

Supposing that linear and nonlinear loads are connected at common coupling point (CCP) [11], under this condition the supply current $\left(i_{s}\right)$ flowing through the transmission line will be the load current $\left(i_{l}\right)$ which is nonsinusoidal. The designed active power filter is a three-phase PWM (pulse with modulation) voltage source inverter (VSI), connected in parallel with the AC source through the common coupling point of (CCP) [12]; the current source equation can be expressed as

$$
i_{s}=i_{l}-i_{f}
$$

The performance of active power filter depends mainly on the technique used to identify and extract the reference current (harmonic current) and the inverter control strategy $[9,13]$. This inverter uses DC voltage capacitor as a supply and can be switched at high frequency to generate the current that will eliminate the harmonic current from the main source. The current waveform used to suppress harmonics is obtained by VSI in the current controlled mode and the interface filter [14].

\section{Proposed Control Scheme}

The block diagram of the proposed shunt APF control scheme is illustrated in Figure 2. In addition, hysteresis controller is used to generate switching signals to control SAPF switches to force the desired current into the system. The compensating currents of active filter are calculated by sensing the load currents, peak voltage, and current of AC source.

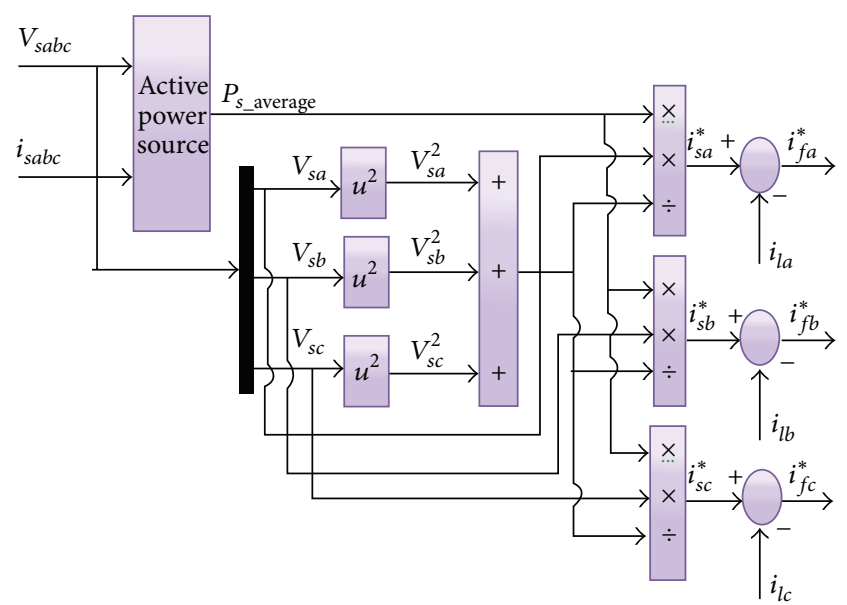

FIGURE 2: Block diagram of the proposed control strategy.

The switching signals based on hysteresis control are obtained in two stages.

Firstly, by subtracting the real load currents $\left(i_{l a}, i_{l b}\right.$, and $\left.i_{l c}\right)$ from the reference current template $\left(i_{s a}^{*}, i_{s b}^{*}\right.$, and $\left.i_{s c}^{*}\right)$, hence, the instantaneous reference current of the APF $\left(i_{f a}^{*}\right.$, $i_{f b}^{*}$, and $\left.i_{f c}^{*}\right)$ is obtained.

Secondly, by subtracting $\left(i_{f a}^{*}, i_{f b}^{*}\right.$, and $\left.i_{f c}^{*}\right)$ from the real harmonic current (current generated by the SAPF), therefore, the switching pulses for voltage source inverter (active power filter) are obtained.

The reference currents are obtained from the instantaneous power and voltages of AC source. The instantaneous voltages of AC source are expressed as follows:

$$
\begin{aligned}
& V_{s a}(t)=V_{s m} \sin (\omega \cdot t), \\
& V_{s b}(t)=V_{s m} \sin \left(\omega \cdot t-\frac{2 \pi}{3}\right), \\
& V_{s c}(t)=V_{s m} \sin \left(\omega \cdot t-\frac{4 \pi}{3}\right) .
\end{aligned}
$$

The source instantaneous power (at Kth sample) is written as presented below:

$$
P_{\text {savg }}(t)=V_{s a}(t) i_{s a}(t)+V_{s b}(t) i_{s b}(t)+V_{s c}(t) i_{s c}(t) .
$$

The required source current is given by the following equation:

$$
\left[\begin{array}{l}
i_{s a}^{*} \\
i_{s b}^{*} \\
i_{s c}^{*}
\end{array}\right]=\frac{P_{s a v g}}{V_{s a}^{2}+V_{s b}^{2}+V_{s c}^{2}}\left[\begin{array}{lll}
1 & 0 & 0 \\
0 & 1 & 0 \\
0 & 0 & 1
\end{array}\right]\left[\begin{array}{c}
v_{s a} \\
v_{s b} \\
v_{s c}
\end{array}\right]
$$

The reference currents (harmonic current) of SAPF is obtained by subtracting the load current from the reference source current as illustrated in the equation below [15]:

$$
\begin{aligned}
& i_{f a}^{*}=i_{s a}^{*}-i_{l a}, \\
& i_{f b}^{*}=i_{s b}^{*}-i_{l b}, \\
& i_{f c}^{*}=i_{s c}^{*}-i_{l c} .
\end{aligned}
$$




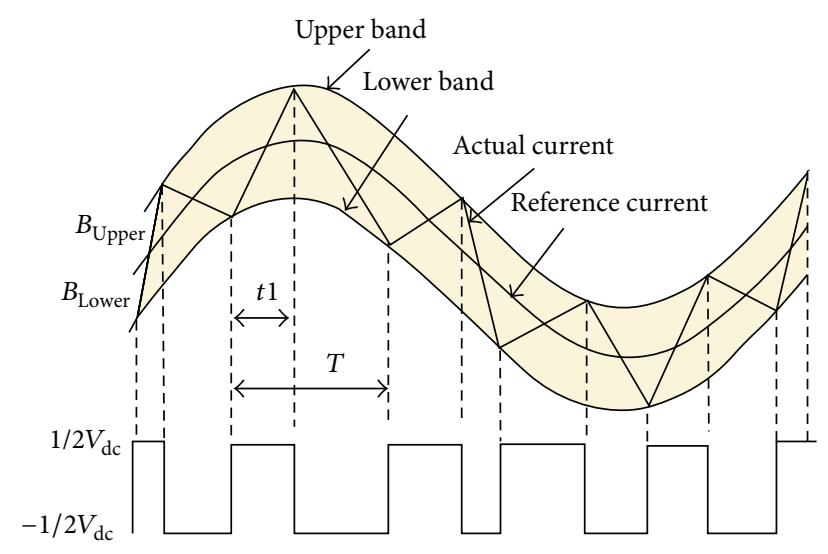

FIGURE 3: Diagram of hysteresis current control.

\section{Modeling of Hysteresis Current Controller}

Several harmonic current control strategies were proposed and used for shunt active filter control. Hysteresis current control strategy can be easily implemented in real-time applications [16]. The scheme of this control strategy used to control the shunt active filter is shown in Figure $3[15,17]$.

This subsystem of hysteresis current controller was developed to generate the switching pulses to control VSI switches by comparing the real current to the reference current. The control scheme gives the switching pattern of active filter switches in order to maintain the real injected current within a desired hysteresis band (HB) as illustrated in Figure 3 [1518]. In the case of positive input current $i_{f}$, the current error exceeds the upper limit of the hysteresis band; thus inverter output should be set as zero, so current error will be forced to the opposite direction without reaching the other outer limit. If this zero condition does not provide the opposite of current error, it will keep forwarding through inner limit to the other outer hysteresis limit. At this time, a reverse polarity of inverter output will be controlled and therefore current direction will be reversed $[14,15,17]$.

The switching frequency of hysteresis current control strategy described and presented above depends mainly on how fast the current changes from upper limit to lower limit of hysteresis band and inversely. Thus, the switching frequency does not remain constant throughout the switching operation but changes along with the current waveform $[15,17,18]$.

Figure 4 shows two-level hysteresis current control method implementation using $S-R$ flip-flop circuits for a three-phase inverter.

The comparator outputs go into flip-flop and the positive inner band limit output goes to set input $(S)$ while the negative inner band limit output goes to reset input $(R)$ of flip-flop. The output of the flip-flop is used to gate the transistors; $Q$ gates the upper transistor and $Q$ bar gates the lower transistor $[19,20]$.

\section{Simulation Results}

MATLAB Simulink software is used to develop and simulate the mathematical model in order to validate and confirm
TABLE 1: Model parameters for unbalanced load.

\begin{tabular}{lccc}
\hline Loads & $R(\Omega)$ & $L(\mathrm{mh})$ & $C(\mathrm{~F})$ \\
\hline Nonlinear load & 150 & 100 & 0.01 \\
Unbalanced load & & & \\
$\quad$ Load 1 & 150 & 100 & 0 \\
Load 2 & 80 & 200 & 0 \\
Load 3 & 100 & 50 & 0 \\
\hline
\end{tabular}
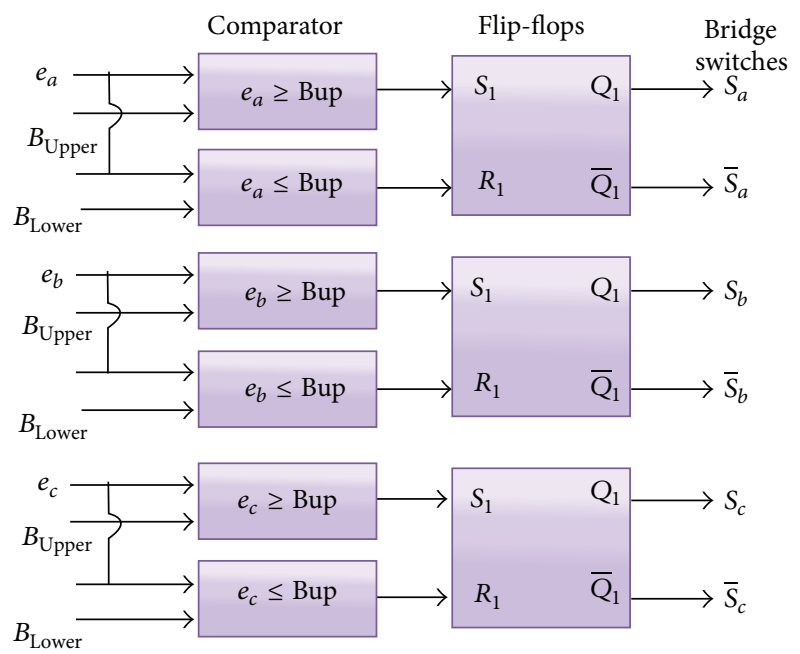

Figure 4: Simplified model of a fixed hysteresis-band control.

the effectiveness and the feasibility of the proposed control algorithm for both balanced and unbalanced nonlinear load conditions. The simulation of active filter operation with different types of loads is conducted using a balanced and sinusoidal three-phase voltages system as shown in Figure 5. The parameters values used in the simulation tests are presented below.

Three-phase source with line-to-line voltage is equal to $380 \mathrm{~V}$ and a frequency of $50 \mathrm{~Hz}$. The source impedance with $R s=0.001 \Omega$ and $L s=0.25 \mathrm{mH}$. The shunt APF is a three-phase MOSFET-based current controlled voltage source inverter with an output AC filter $(L f=35 \mathrm{mH}, R f=$ $3.5 \Omega$ ) and two DC voltage $\pm 2 V_{\mathrm{dc}}= \pm 650 \mathrm{~V}$.

The load is an uncontrolled three-phase bridge rectifier with $R-L-C$ load with three-phase unbalanced loads as presented in Table 1.

Figures 5 and 6 have shown the voltage source, and the obtained results have shown a high filtering quality of harmonic currents. The different waveforms obtained by the proposed control method are illustrated in Figures 7-21.

From these waveforms, it can be noted that the behavior of the active filter is analysed and studied in steady-state operation. Figures 16, 17, and 18 show load currents, active filter compensation currents, and source currents for 3 phases with a neutral wire. The THD of the source current is the same as that of the load current when the filter is not connected $(12.55 \%$ for phase- $a, 10.58 \%$ for phase- $b$, and $10.53 \%$ for phase-c); these values are well above the IEEE 519 standards. In order to reduce the harmonic pollution within the IEEE 


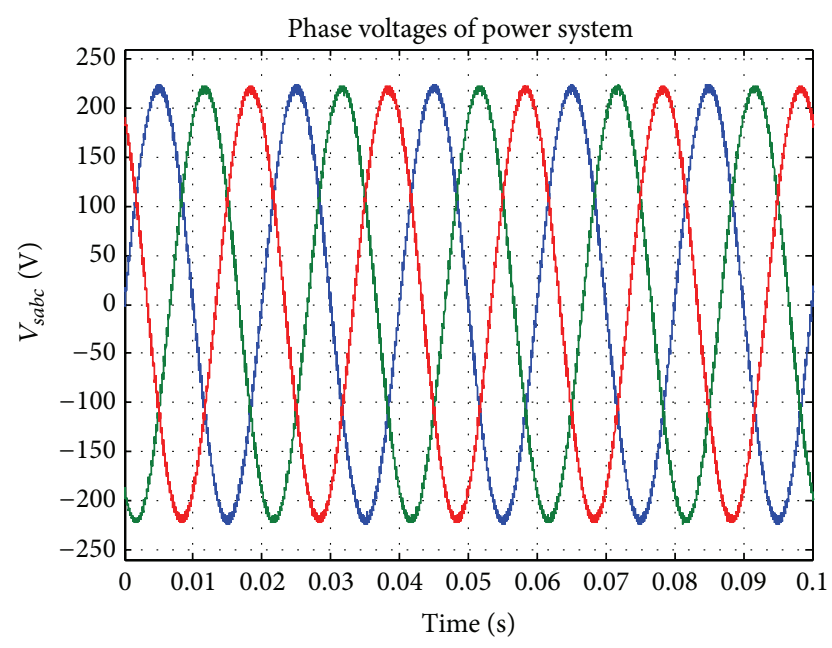

FIGURE 5: Power system phase voltages.

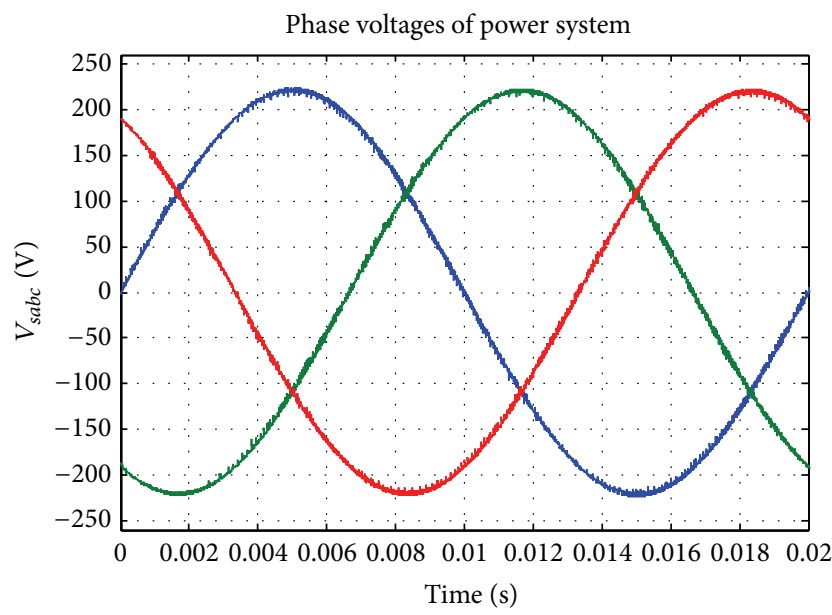

FIgURE 6: Zoom of power system phase voltages.

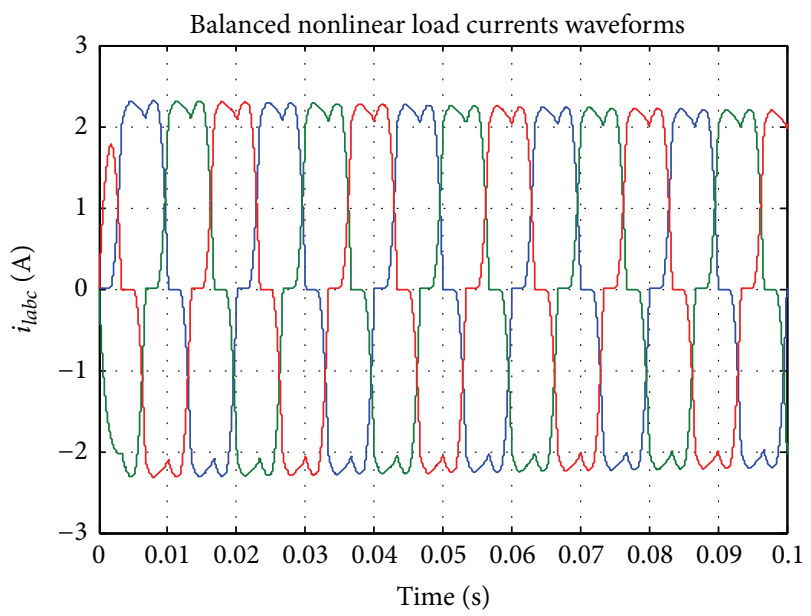

FIGURE 7: Balanced nonlinear load currents waveforms.

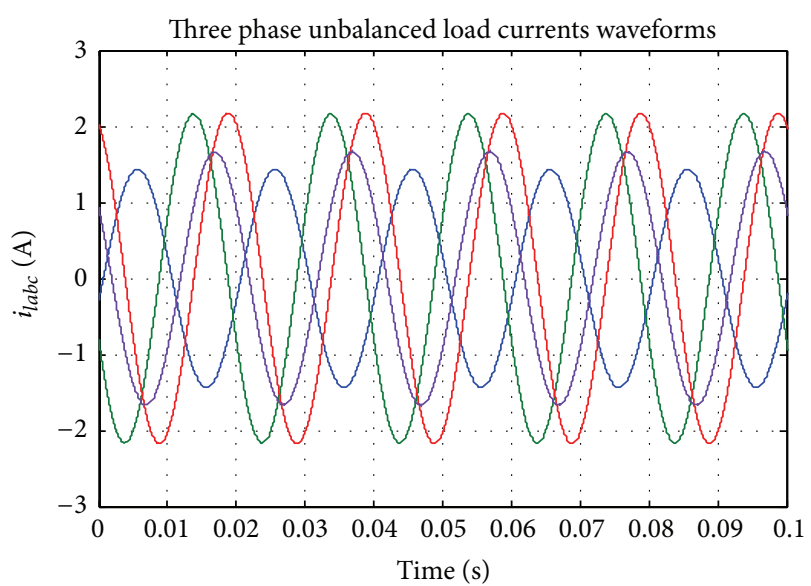

FIgURE 8: Three-phase unbalanced nonlinear and neutral load currents waveforms.

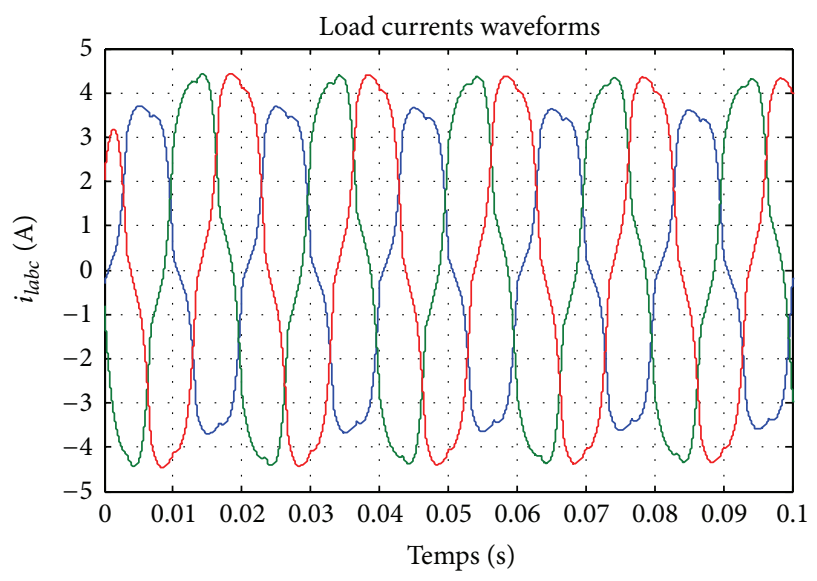

FIgURE 9: Total load currents waveform.

519 standards, the proposed algorithm based on SAPF is introduced and the real active filter current is illustrated in Figure 13. By injecting the required harmonic current to the main source, the source current becomes sinusoidal as shown in Figure 14. Connecting the active filter with the proposed control algorithm, the THD of the source current is improved to reach $1.69 \%$ in phase- $a, 1.89 \%$ in phase- $b$, and $1.85 \%$ in phase- $c$, which is within the IEEE 519 standards. However, with the use of conventional method $p q$, the THD of the source current is still unsatisfactory with the following values: $6.84 \%$ in phase- $a, 6.09 \%$ in phase- $b$, and $5.56 \%$ in phase- $c$. This indeed shows the potency of the proposed method to perform well compared to conventional methods in reducing the value of THD. The harmonic frequency spectrum of the compensated source current is shown in Figures 19-21.

Table 2 outlines comparative results obtained using the proposed approach against conventional methods.

\section{Conclusion}

The work presented in this paper has demonstrated and confirmed the effectiveness of the proposed control method for 


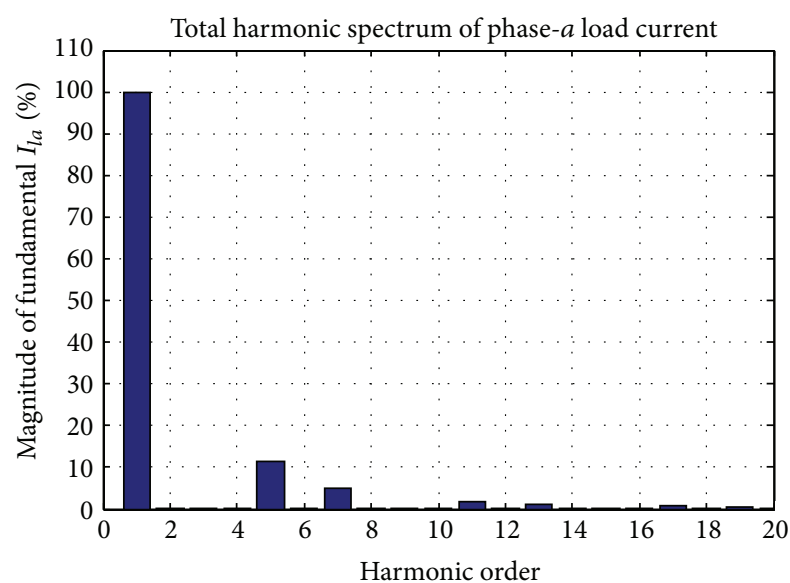

FIGURE 10: Frequency spectrum of phase- $a$ load current.

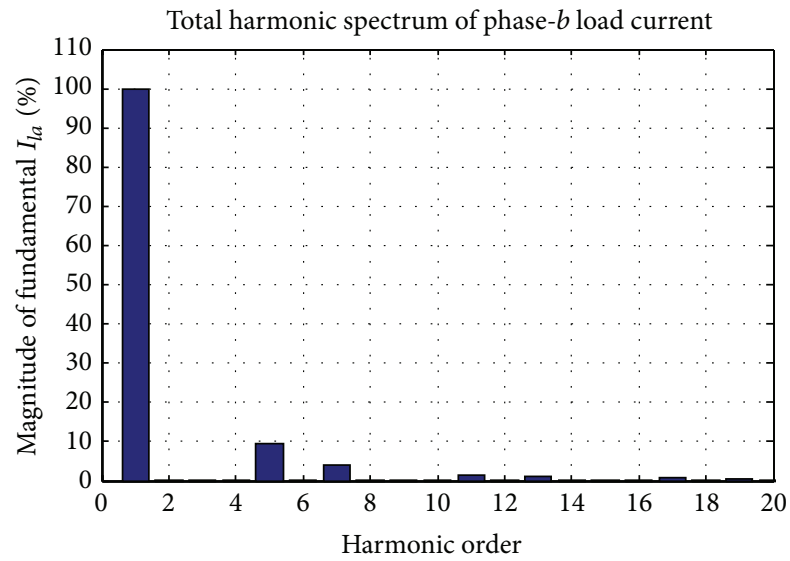

FIGURE 11: Frequency spectrum of phase- $b$ load current.

TABLE 2: The comparative results of THD.

\begin{tabular}{rccc}
\hline & $\begin{array}{c}\text { Without } \\
\text { APF }\end{array}$ & $\begin{array}{c}\text { With conventional } \\
\text { method } p q\end{array}$ & $\begin{array}{r}\text { With the } \\
\text { proposed } \\
\text { method }\end{array}$ \\
\hline THD & & & \\
Phase- $a$ & $12.55 \%$ & $6.84 \%$ & $1.69 \%$ \\
Phase- $b$ & $10.58 \%$ & $6.09 \%$ & $1.89 \%$ \\
Phase- $c$ & $10.53 \%$ & $5.56 \%$ & $1.85 \%$ \\
\hline
\end{tabular}

a shunt active filter application under unbalanced nonlinear loads. The tests carried out by computer simulation have verified the efficiency of the proposed control scheme. The obtained results prove that the purpose of proposed control algorithm has been successfully achieved under unbalanced or balanced load. The THD of the source current is reduced below 5\% which is the limit imposed by the IEEE 519 standards (1992) for both balanced and unbalanced loads using the APF. Furthermore, the proposed control strategy is very simple and robust.

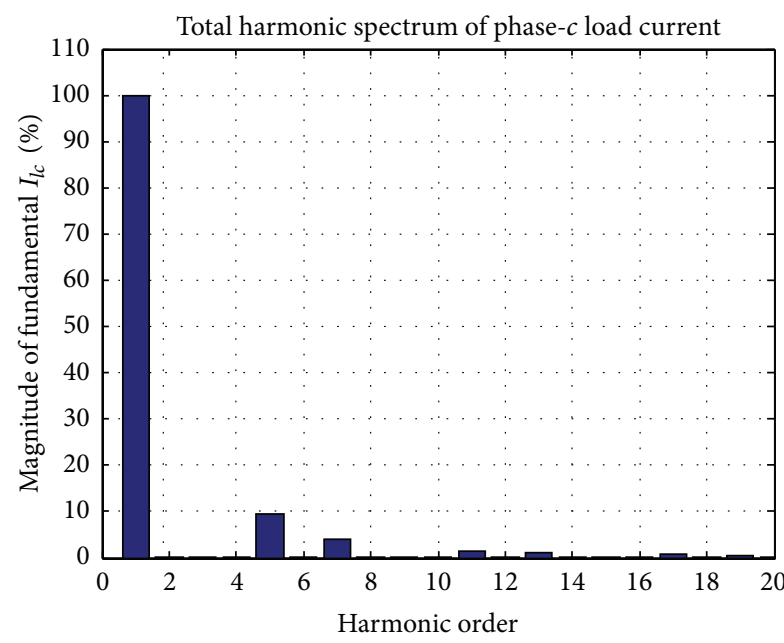

FIGURE 12: Frequency spectrum of phase-c load current.

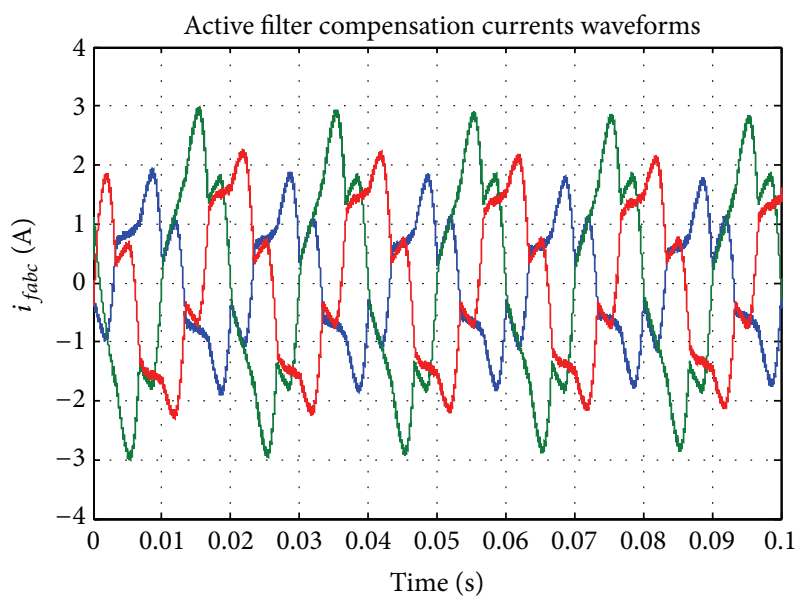

FIGURE 13: Active filter currents waveform with the proposed control.

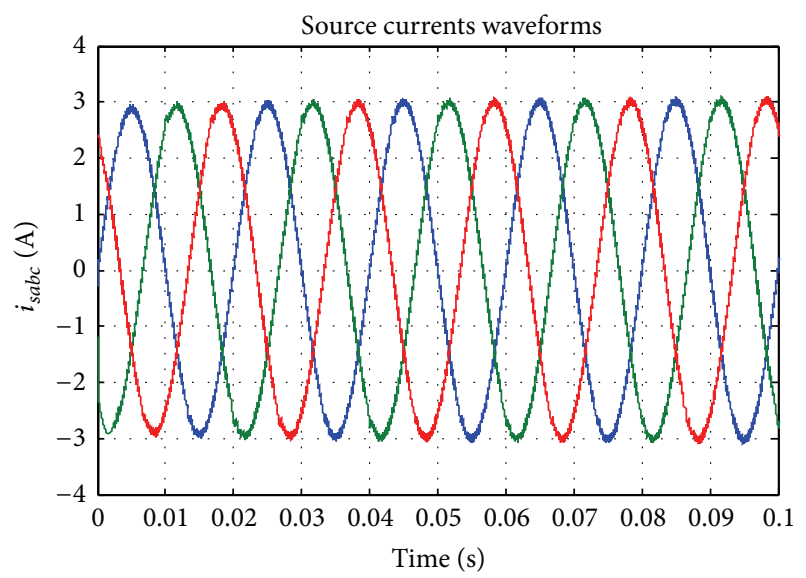

FIGURE 14: Source currents waveforms. 


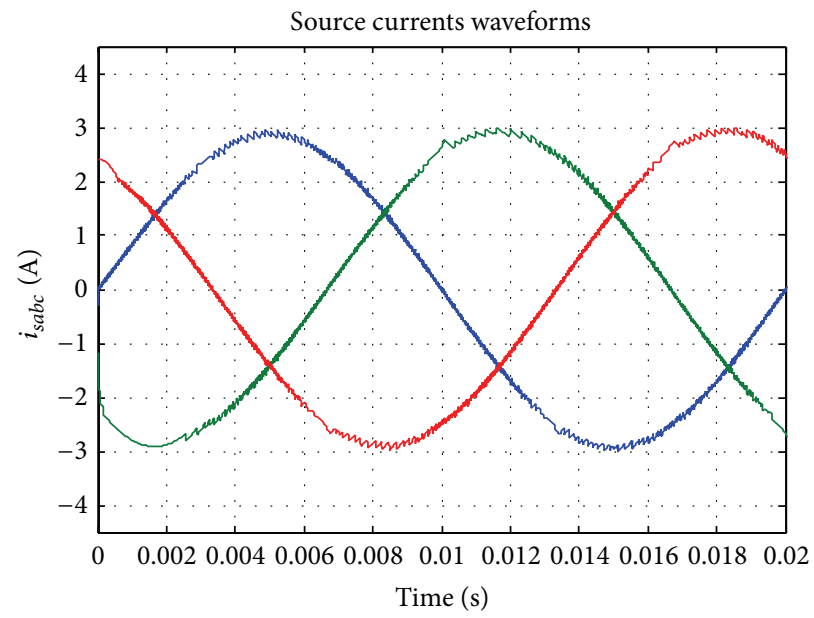

FIGURE 15: Zoom of source currents waveform.

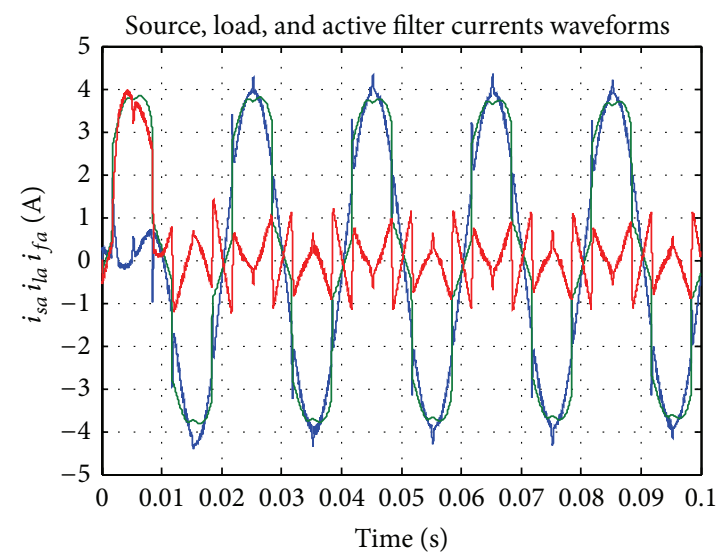

(a) With conventional method $p q$

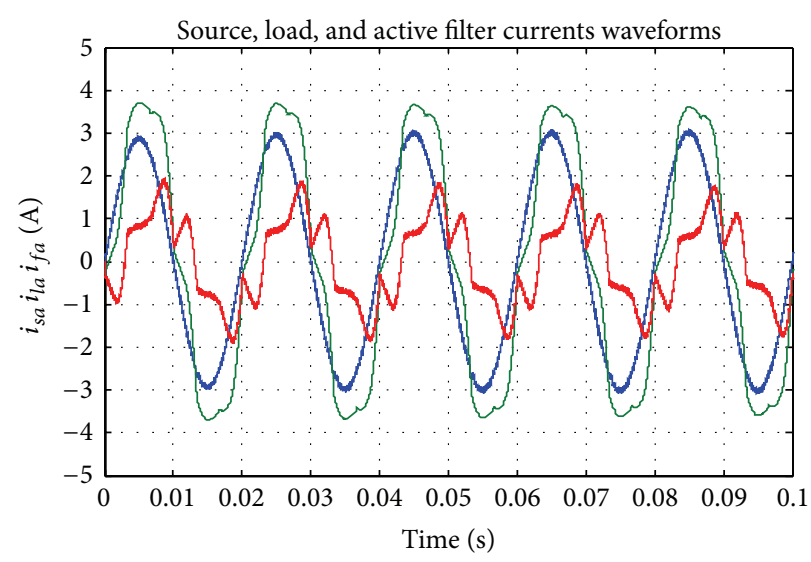

(b) With the proposed control scheme

FIGURE 16: Source, load, and active filter currents of phase- $a$ waveforms.

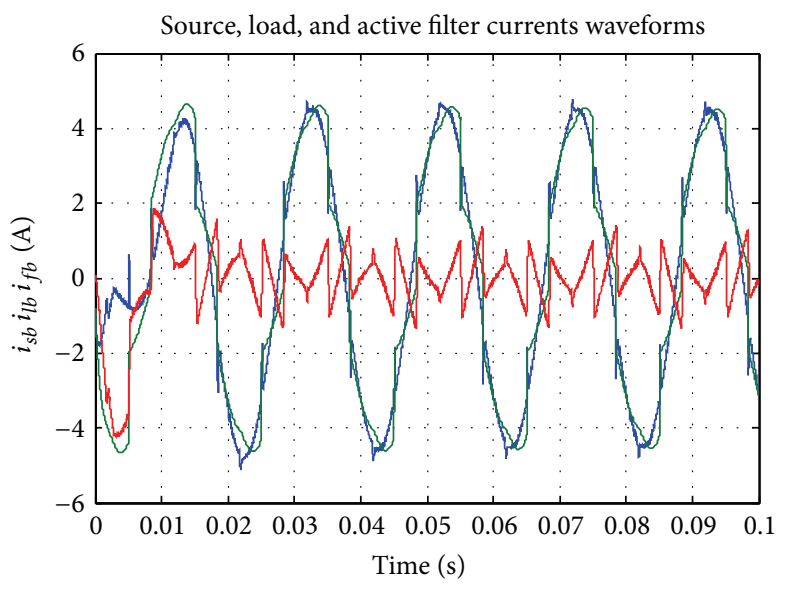

(a) With conventional method $p q$

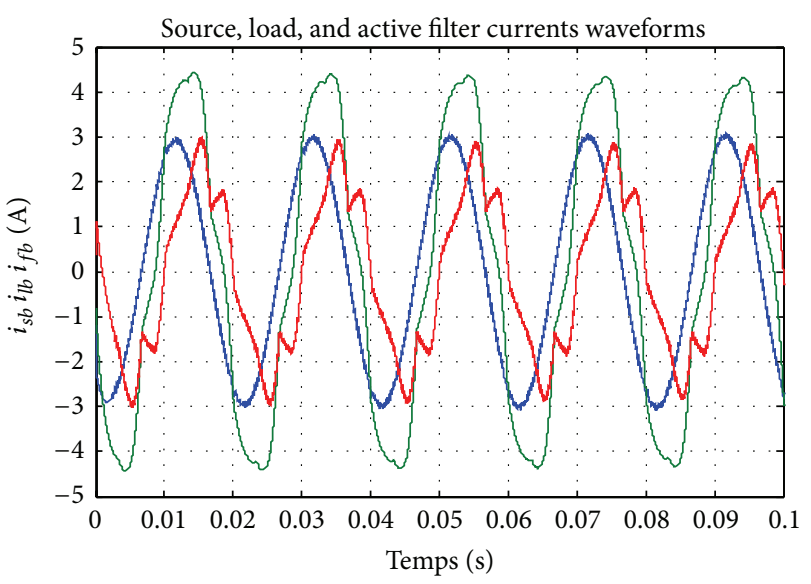

(b) With the proposed control scheme

FIGURE 17: Source, load, and active filter currents of phase- $b$ waveforms. 


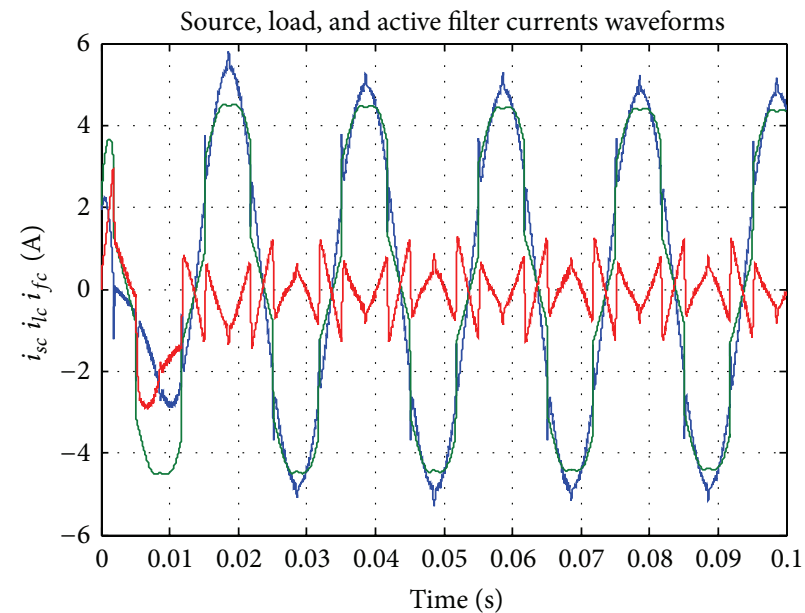

(a) With conventional method $p q$

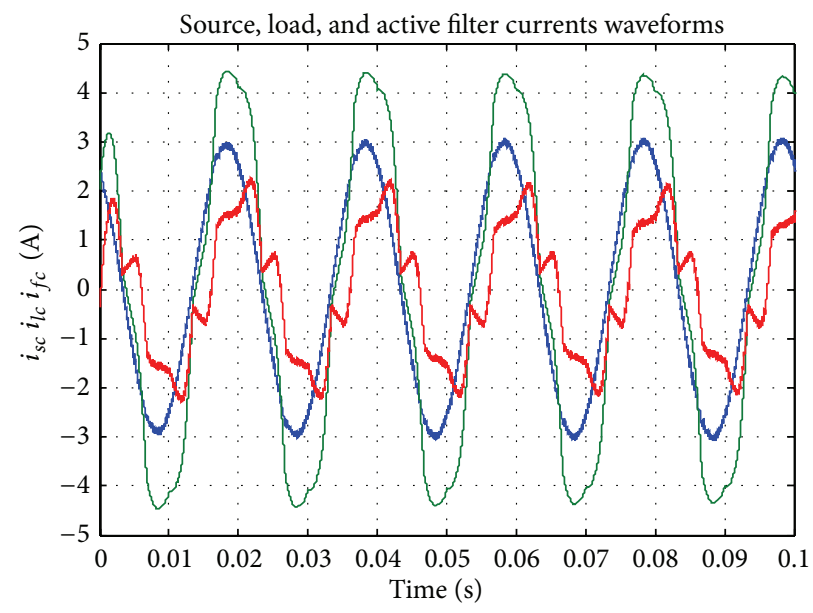

(b) With the proposed control scheme

FIGURE 18: Source, load, and active filter currents of phase-c waveforms.

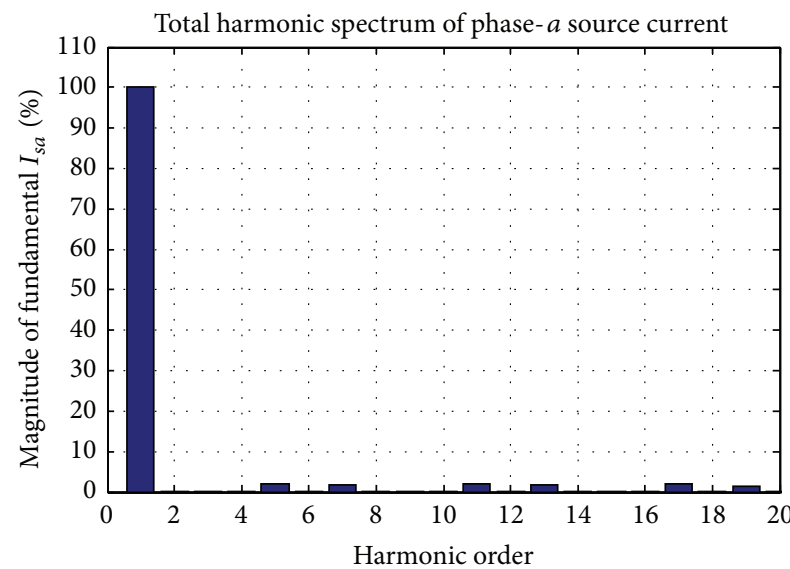

(a) With conventional method $p q$

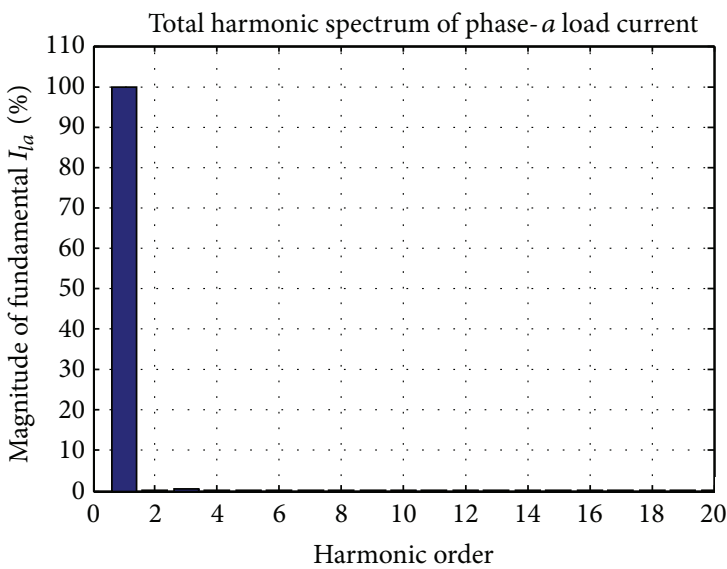

(b) With the proposed control scheme

FIGURE 19: Frequency spectrum phase- $a$ source current.

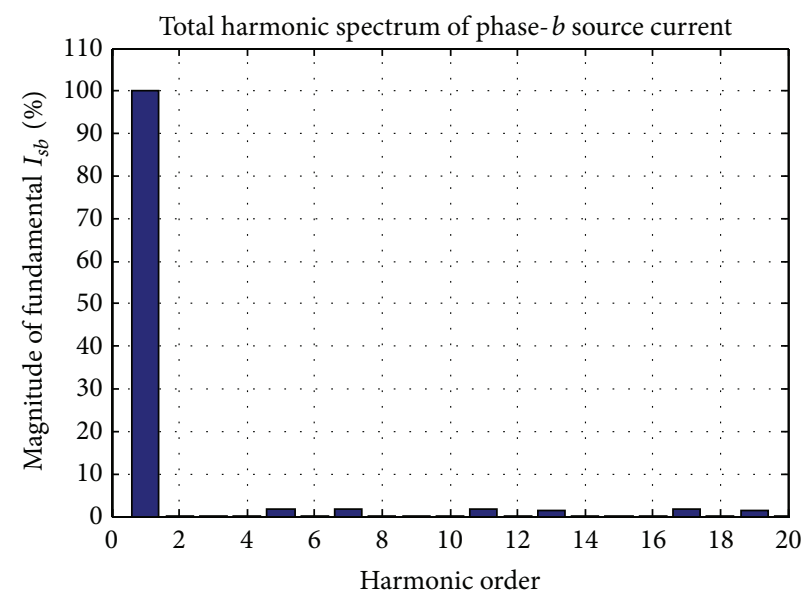

(a) With conventional method $p q$

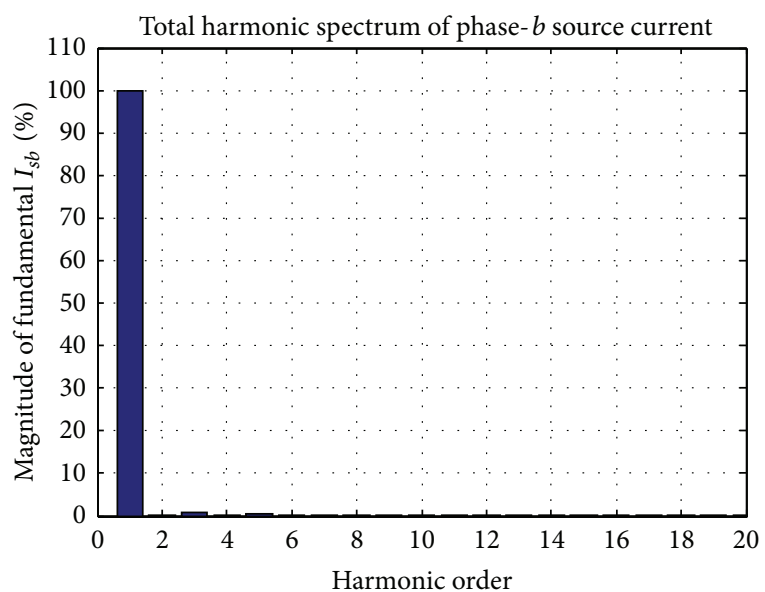

(b) With the proposed control scheme

FIGURE 20: Frequency spectrum phase- $b$ source current. 


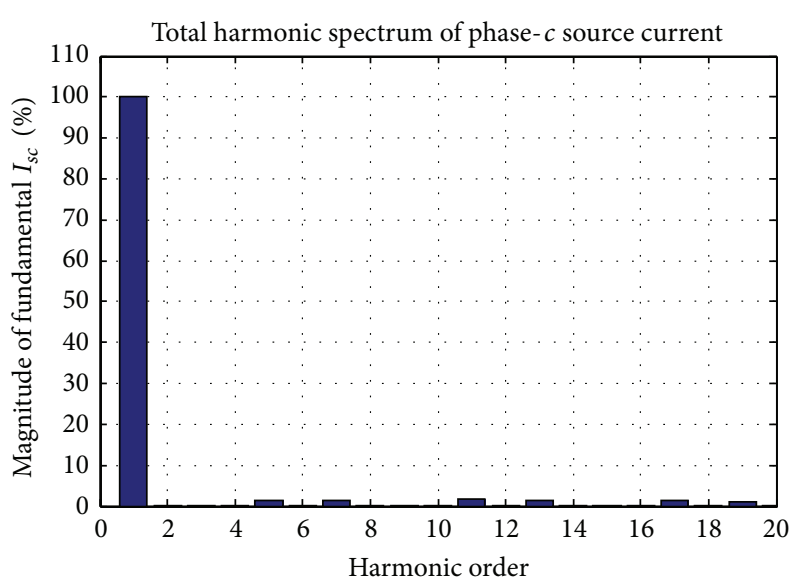

(a) With conventional method $p q$

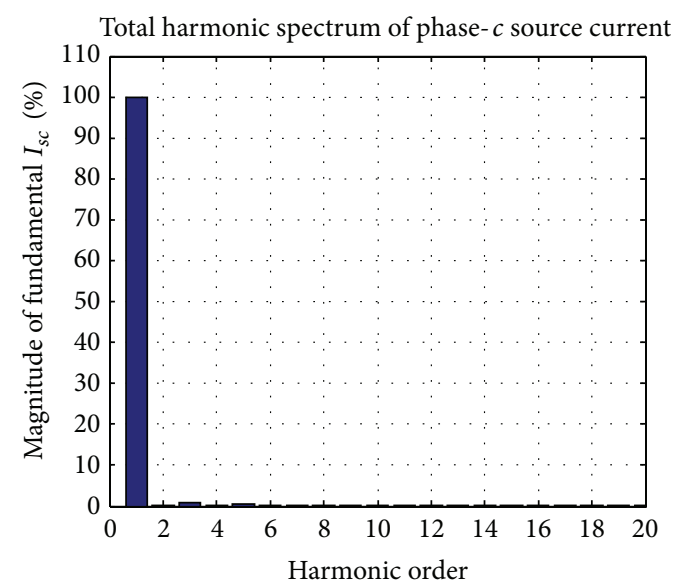

(b) With the proposed control scheme

FIGURE 21: Frequency spectrum of phase- $c$ source current.

\section{Conflict of Interests}

The authors declare that there is no conflict of interests regarding the publication of this paper.

\section{Acknowledgments}

The authors like to thank both the MIPS Laboratory (France) for the technical support and the Algerian General Agency of Research for its financial support.

\section{References}

[1] G. Adam, A. G. Stan, and G. Livinţ, "A Matlab-Simulink approach to shunt active power filters," in Proceedings of the 25th European Conference on Modelling and Simulation (ECMS '11), pp. 205-210, Krakow, Poland, June 2011.

[2] E. Özdemi, K. Mura, and Ş. Özdemir, "Active power filter for power compensation under non-ideal mains voltages," in Proceedings of the 11th Mediterranean Conference on Control and Automation (MED '03), 2003.

[3] J. L. Afonso, C. Couto, and J. S. Martins, "Active filters with control based on the $\mathrm{p}-\mathrm{q}$ theory," IEEE Industrial Electronics Society Newsletter, vol. 47, no. 3, pp. 5-10, 2000.

[4] M. I. M. Montero, E. R. Cadaval, and F. B. González, "Comparison of control strategies for shunt active power filters in three-phase four-wire systems," IEEE Transactions on Power Electronics, vol. 22, no. 1, pp. 229-236, 2007.

[5] R. A. Hooshmand and M. Torabian Esfahani, "A new combined method in active filter design for power quality improvement in power systems," ISA Transactions, vol. 50, no. 2, pp. 150-158, 2011.

[6] M. Ucar and E. Ozdemir, "Control of a 3-phase 4-leg active power filter under non-ideal mains voltage condition," Electric Power Systems Research, vol. 78, no. 1, pp. 58-73, 2008.

[7] K. M. Mahajan, S. George, and S. Thale, "Simulation of shunt active filter using D-Q theory," in Proceedings of the 3rd Biennial National Conference (NCNTE '12), pp. 21-25, 2012.
[8] H. Akagi, E. H. Watanabe, and M. Aredes, Instantaneous Power Theory and Applications to Power Conditioning, vol. 4, IEEE Press, 2007.

[9] V. F. Corasaniti, M. B. Barbieri, P. L. Arnera, and M. I. Valla, "Hybrid power filter to enhance power quality in a mediumvoltage distribution network," IEEE Transactions on Industrial Electronics, vol. 56, no. 8, pp. 2885-2893, 2009.

[10] L. Merabet, S. Saad, D. O. Abdeslam, and A. Omeiri, "A comparative study of harmonic currents extraction by simulation and implementation," International Journal of Electrical Power and Energy Systems, vol. 53, no. 1, pp. 507-514, 2013.

[11] R. Belaidia, B. A. Haddouchea, and H. Guendouza, "Fuzzy logic controller based three-phase shunt active power filter for compensating harmonics and reactive power under unbalanced mains voltages," Energy Procedia, vol. 18, pp. 560-570, 2012.

[12] E. L. Mercy, R. Karthick, and S. Arumugam, "A comparative performance analysis of four control algorithms for a three phase shunt active power filter," International Journal of Computer Science and Network Security, vol. 10, no. 6, 2010.

[13] G. Sincy and A. Vivek, "A novel, DSP based algorithm for optimizing the harmonics and reactive power under nonsinusoidal supply voltage conditions," IEEE Transactions on Power Delivery, vol. 20, no. 4, pp. 2526-2534, 2005.

[14] A. Singh and S. kumar, "Performance investigation of active power line conditioner using simulink," International Journal of Emerging Technology and Advanced Engineering, vol. 2, no. 10, 2012.

[15] W. Huaisheng and X. Huifeng, "A novel double hysteresis current control method for active power filter," Physics Procedia, vol. 24, pp. 572-579, 2012.

[16] N. Senthilnathan and T. Manigandan, "A novel control strategy for line harmonic reduction using three phase shunt active filter with balanced and unbalanced supply," European Journal of Scientific Research, vol. 67, no. 3, pp. 456-466, 2012.

[17] S. Lotfi and M. Sajedi, "Role of a shunt active filter in power quality improvement and power factor correction," Journal of Basic and Applied Scientific Research, vol. 2, no. 2, pp. 1015-1020, 2012.

[18] P. Karuppanan, S. K. Ram, and K. Mahapatra, "Three level hysteresis current controller based active power filter for harmonic 
compensation," in Proceedings of the International Conference on Emerging Trends in Electrical and Computer Technology (ICETECT '11), pp. 407-412, Tamil Nadu, India, March 2011.

[19] T. Midtsund, Control of power electronic converters in distributed power generation systems [M.Sc thesis], Norwegian University of Science, 2010.

[20] F. Ucar, R. Coteli, and B. Dandil, "Three level inverter based shunt active power filter using multi-level hysteresis band current controller," Electrical Review, vol. 88, no. 11A, pp. 227231, 2012. 

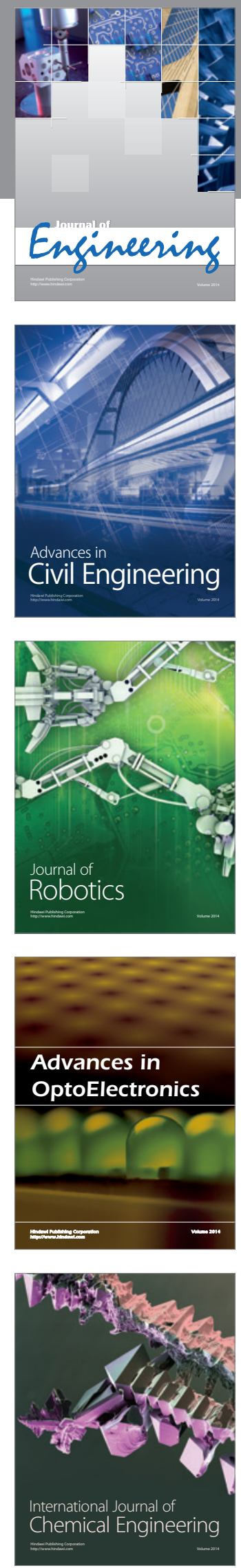

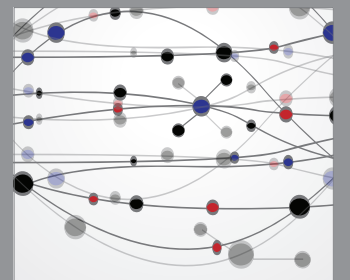

The Scientific World Journal
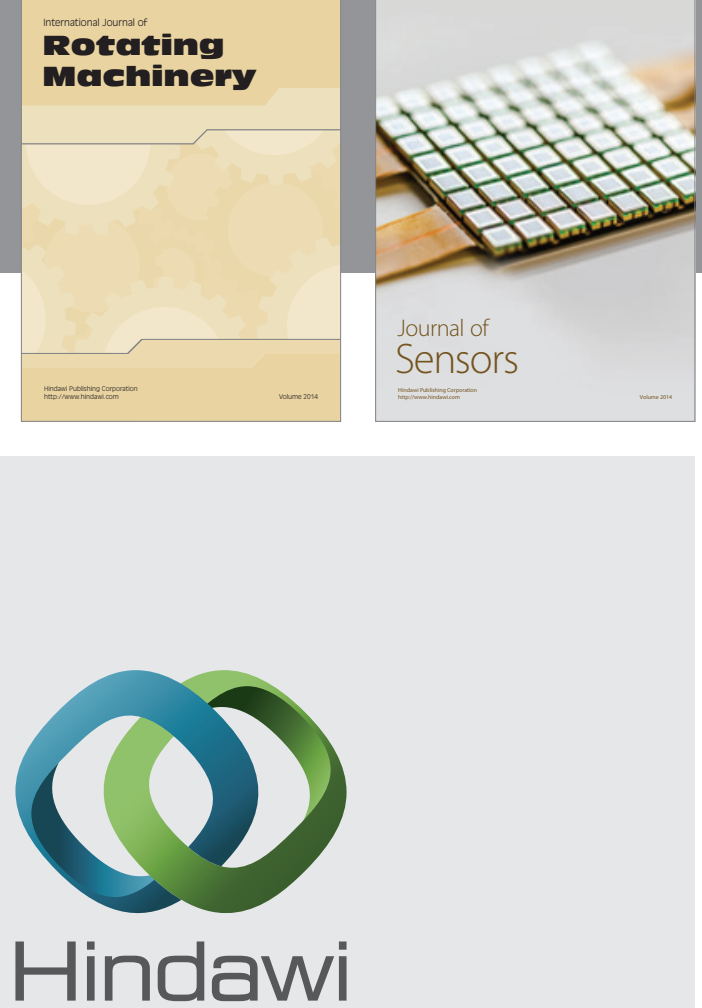

Submit your manuscripts at http://www.hindawi.com
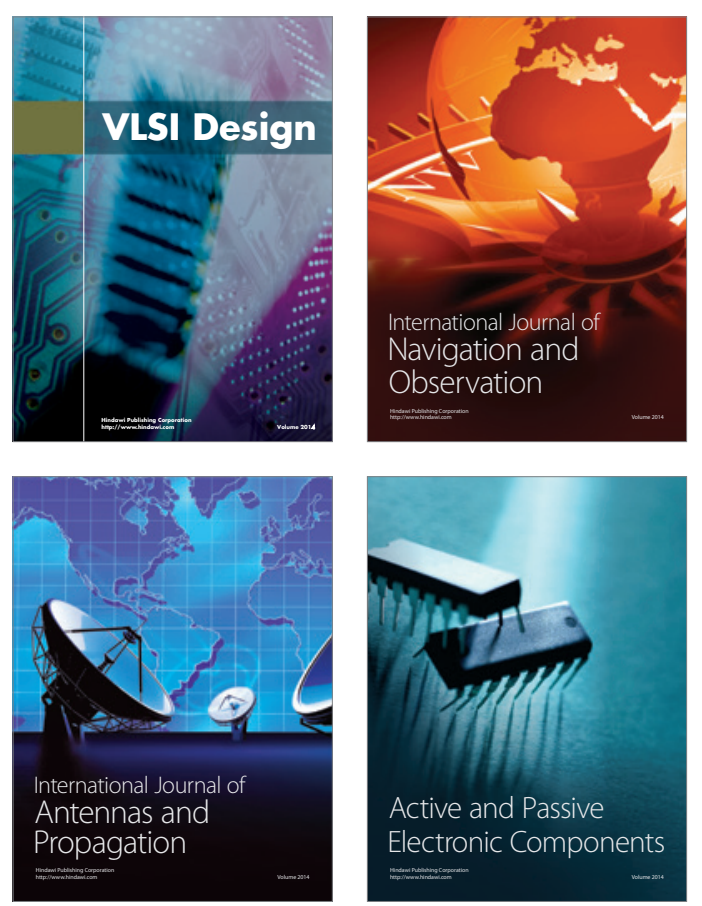
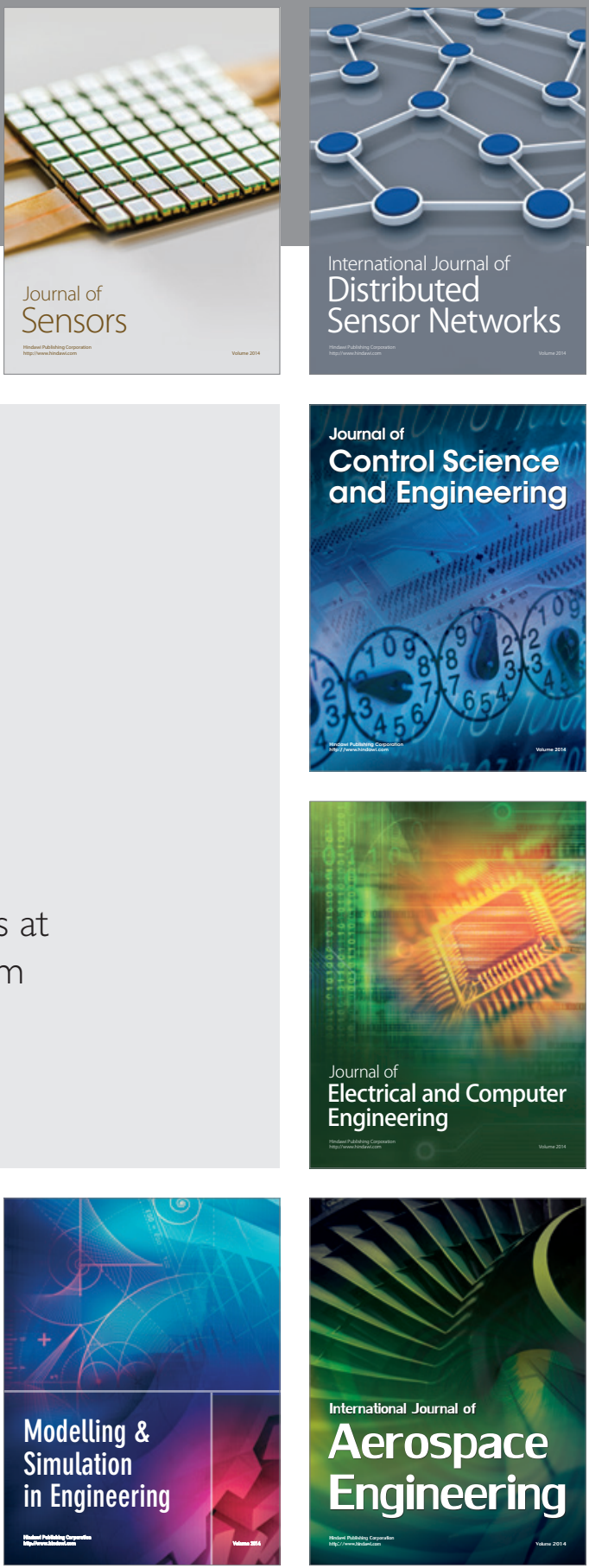

Journal of

Control Science

and Engineering
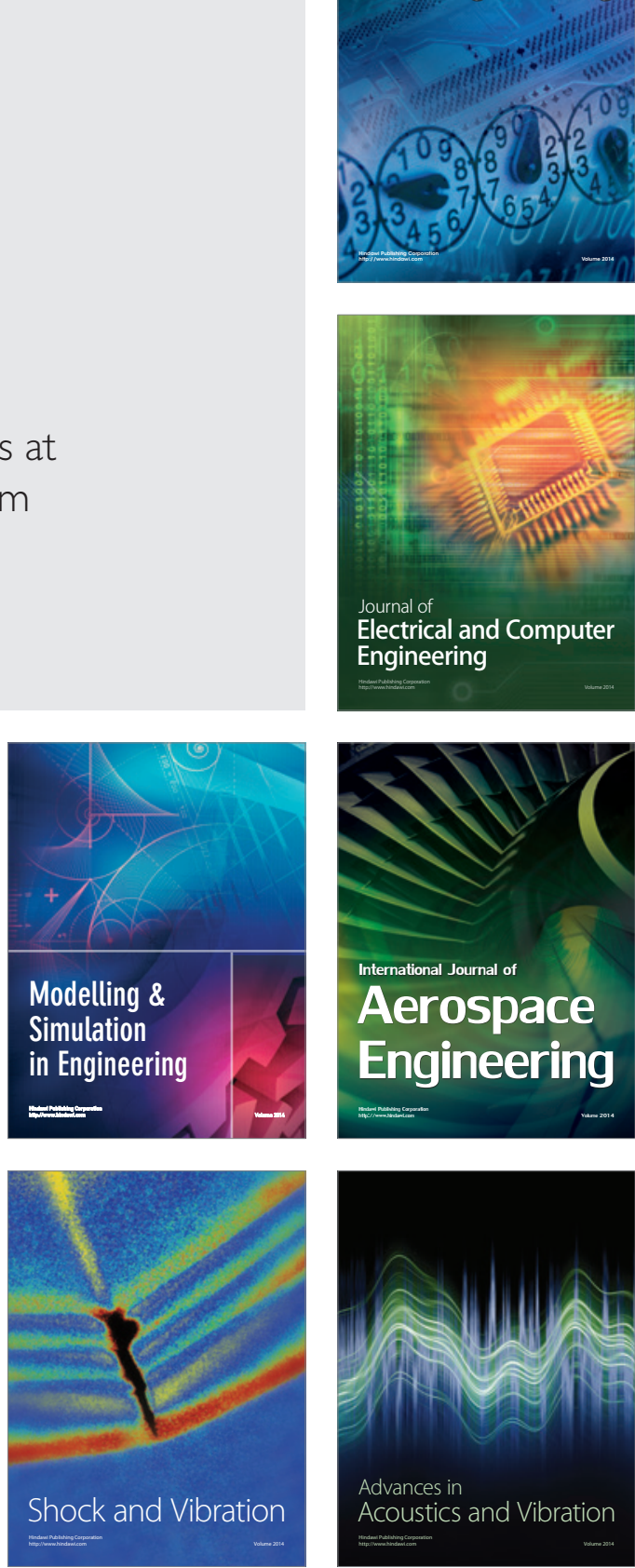